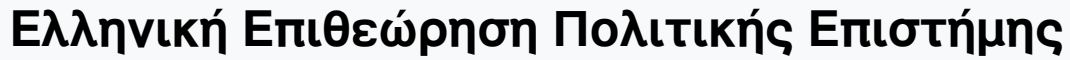

Tón. 29, Ap. 1 (2007)

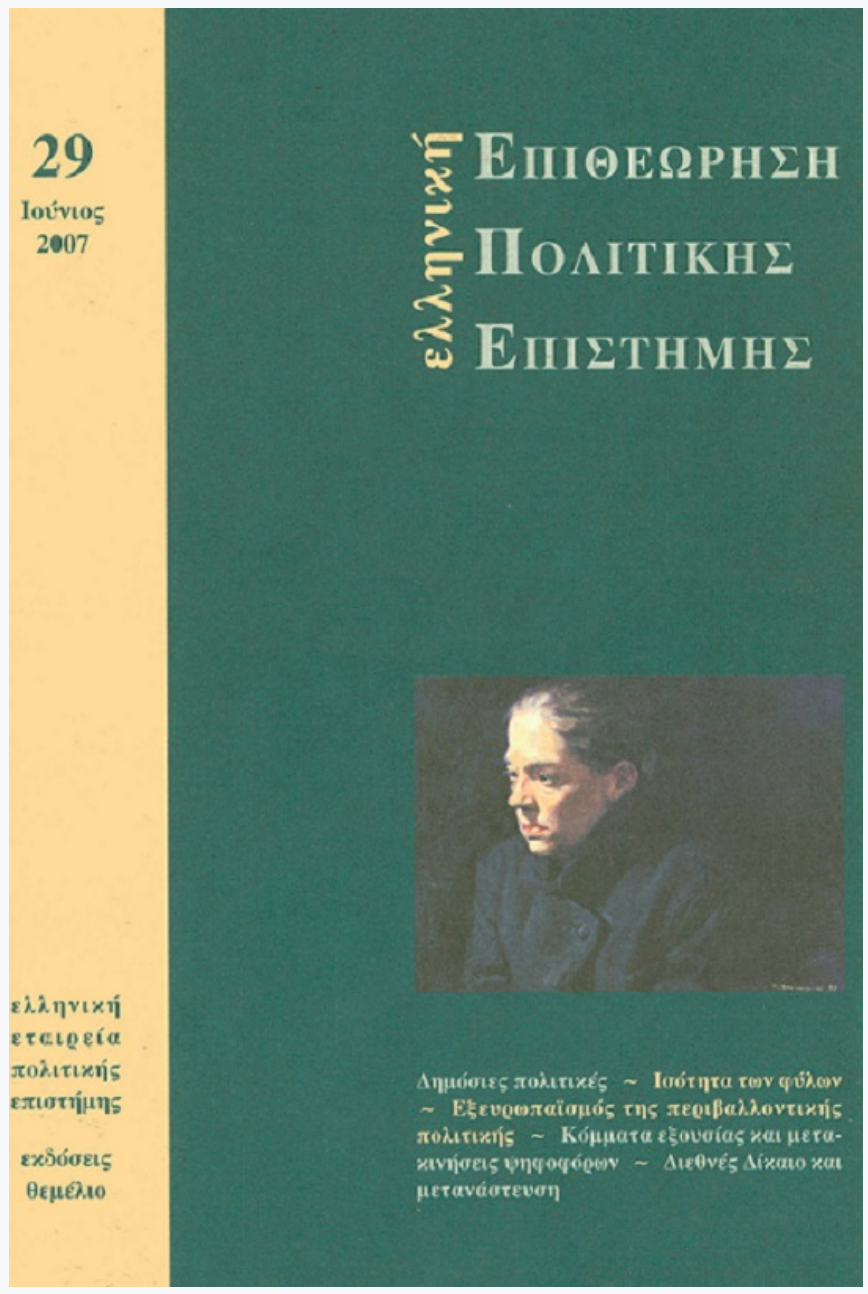

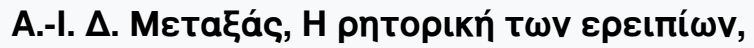

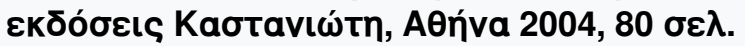

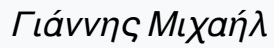

doi: $10.12681 / \mathrm{hpsa} .14652$

Copyright $\odot$ 2017, Гıávvnc Mıхań入

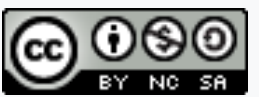

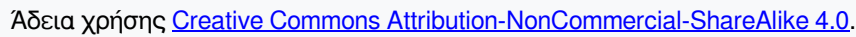

\section{Bıßлıүрачıкń avaфopá:}

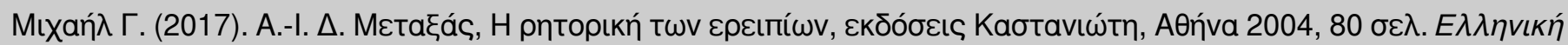

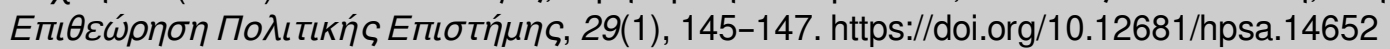




\section{BIBAIOKPITIKE $\Sigma$}

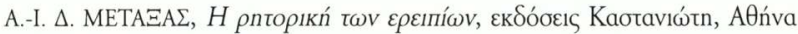
2004, 80 бع $\lambda$.

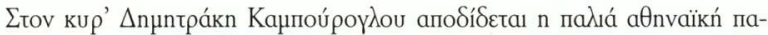

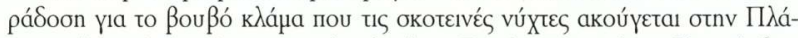

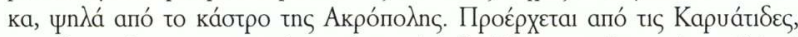

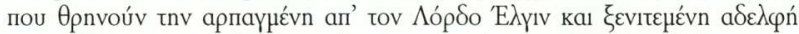

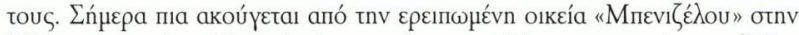

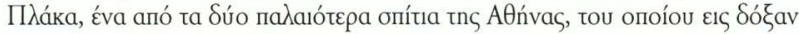

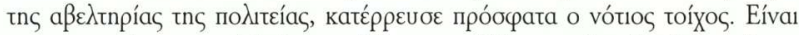

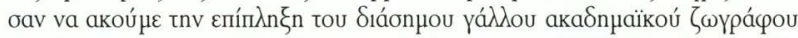

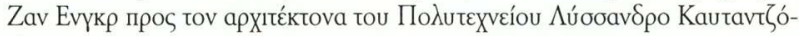

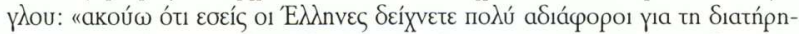

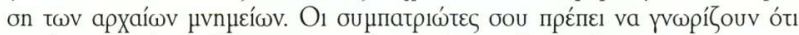

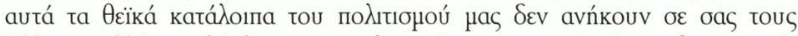

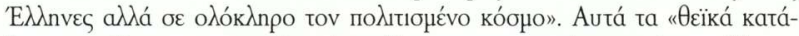

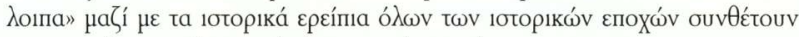

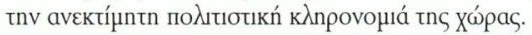

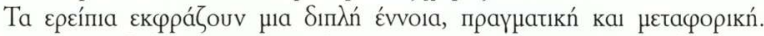

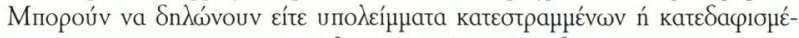

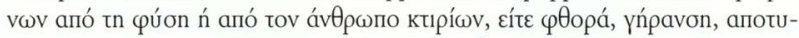

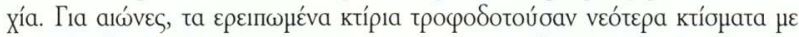

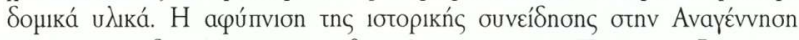

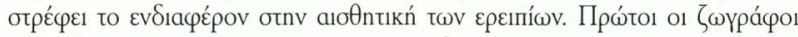

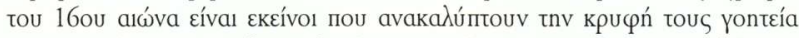

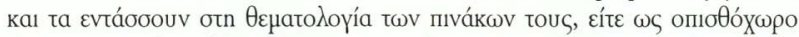

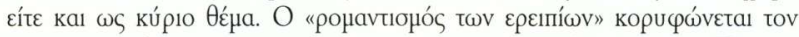

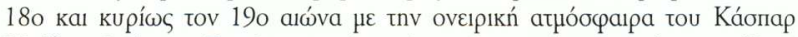

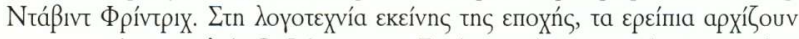

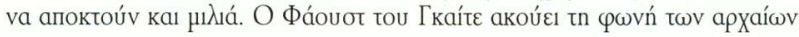




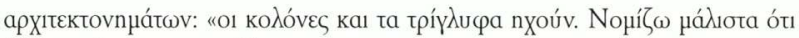

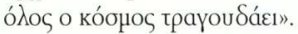

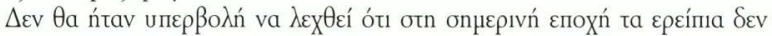

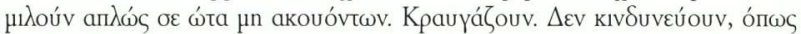

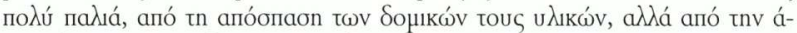

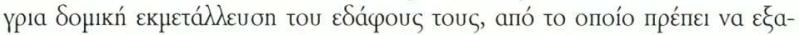

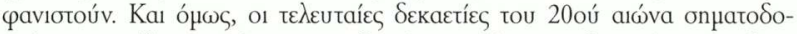

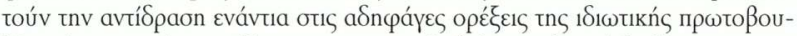

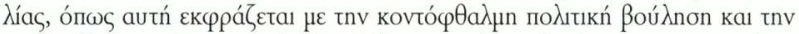

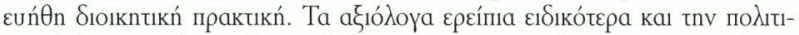

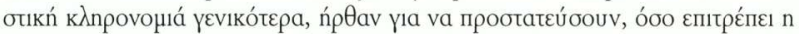

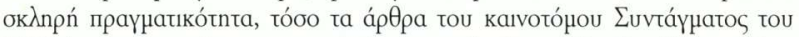

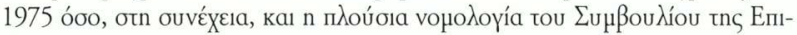
кpatzías.

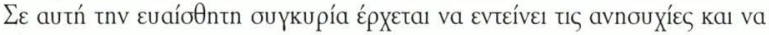

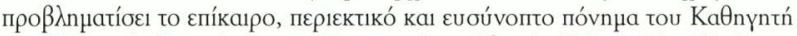

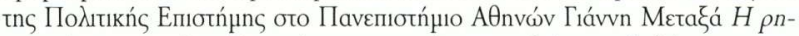

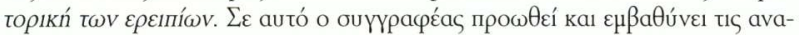

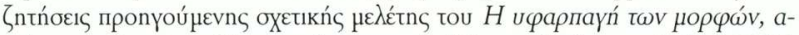

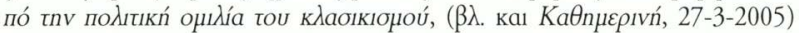

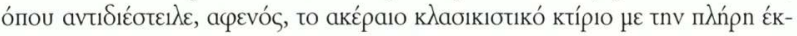

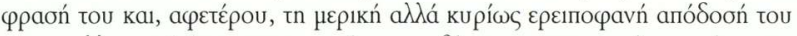

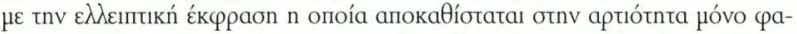

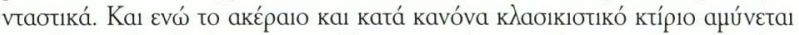

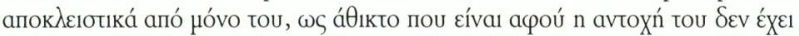

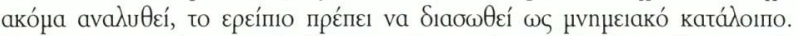

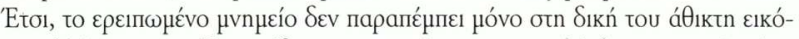

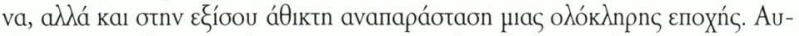

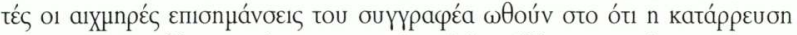

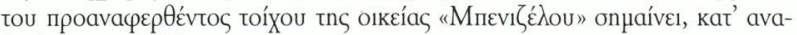

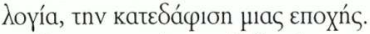

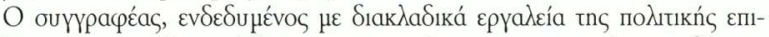

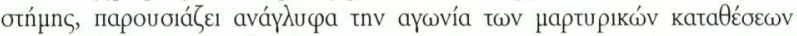

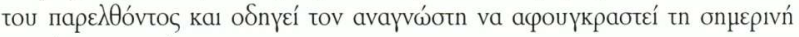

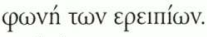

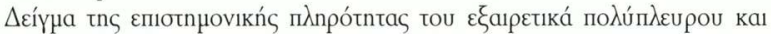

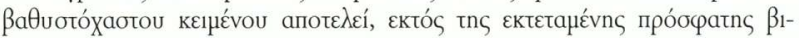




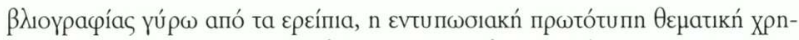

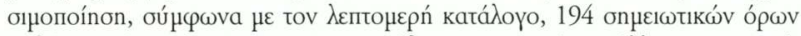

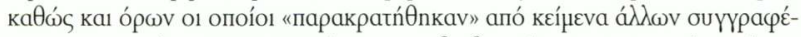

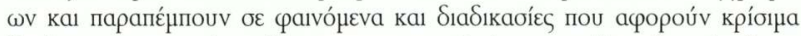

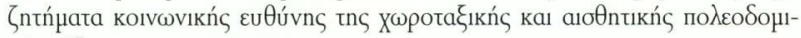
kńs tá\}nc.

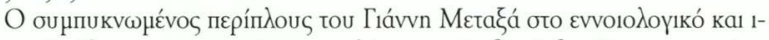

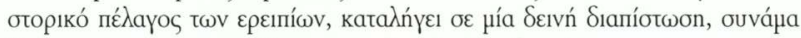

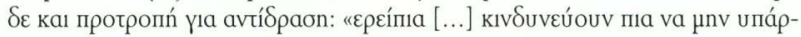

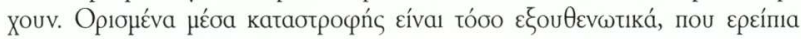

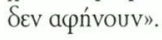

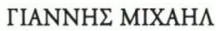

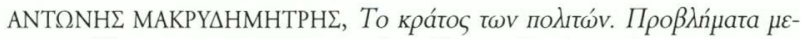

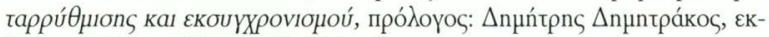

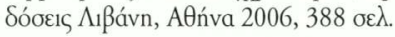

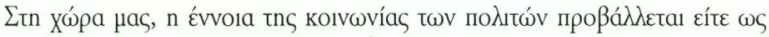

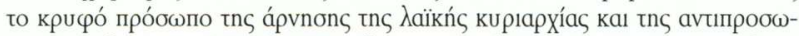

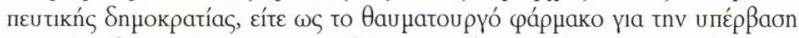

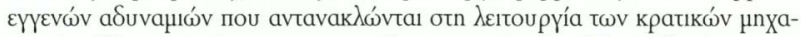

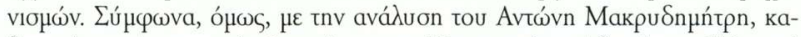

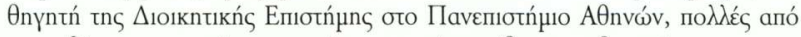

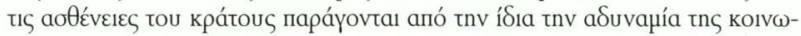

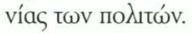

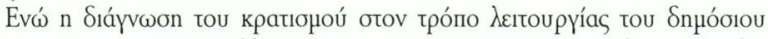

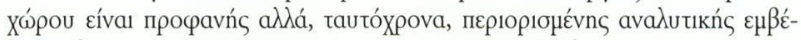

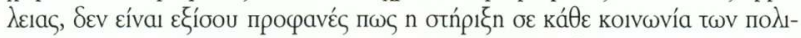

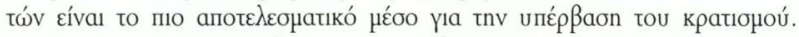

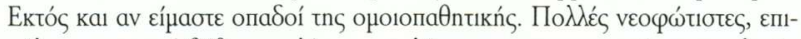

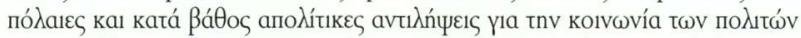

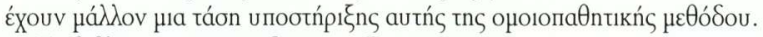

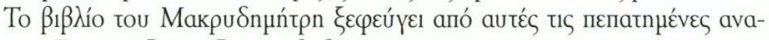

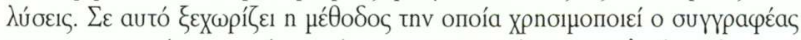

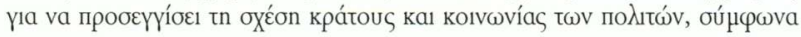

